\title{
Formation of soluble amyloid oligomers and amyloid fibrils by the multifunctional protein vitronectin
}

\author{
Thuzar M Shin11, J Mario Isas', Chia-Ling Hsieh¹, Rakez Kayed², \\ Charles G Glabe ${ }^{3}$, Ralf Langen*1 and Jeannie Chen*1
}

Address: 1Zilhka Neurogenetic Institute, University of Southern California, Los Angeles, California 90033, USA, ${ }^{2}$ Department of Neurology, University of Texas Medical Branch School of Medicine, Galveston, Texas 77555, USA and ${ }^{3}$ Department of Molecular Biology and Biochemistry, University of California, Irvine, California 92697, USA

Email: Thuzar M Shin - thuzar@usc.edu; J Mario Isas - isas@usc.edu; Chia-Ling Hsieh - chialing@usc.edu; Rakez Kayed - rakayed@utmb.edu; Charles G Glabe - cglabe@uci.edu; Ralf Langen* - langen@usc.edu; Jeannie Chen* - jeannie@usc.edu

* Corresponding authors

Published: 21 October 2008

Molecular Neurodegeneration 2008, 3:16 doi:10.1186/1750-1326-3-16
Received: 17 September 2008

Accepted: 21 October 2008

This article is available from: http://www.molecularneurodegeneration.com/content/3/1/16

(C) 2008 Shin et al; licensee BioMed Central Ltd.

This is an Open Access article distributed under the terms of the Creative Commons Attribution License (http://creativecommons.org/licenses/by/2.0), which permits unrestricted use, distribution, and reproduction in any medium, provided the original work is properly cited.

\begin{abstract}
Background: The multifunctional protein vitronectin is present within the deposits associated with Alzheimer disease (AD), age-related macular degeneration (AMD), atherosclerosis, systemic amyloidoses, and glomerulonephritis. The extent to which vitronectin contributes to amyloid formation within these plaques, which contain misfolded, amyloidogenic proteins, and the role of vitronectin in the pathophysiology of the aforementioned diseases is currently unknown. The investigation of vitronectin aggregation is significant since the formation of oligomeric and fibrillar structures are common features of amyloid proteins.

Results: We observed vitronectin immunoreactivity in senile plaques of $A D$ brain, which exhibited overlap with the amyloid fibril-specific $O C$ antibody, suggesting that vitronectin is deposited at sites of amyloid formation. Of particular interest is the growing body of evidence indicating that soluble nonfibrillar oligomers may be responsible for the development and progression of amyloid diseases. In this study we demonstrate that both plasma-purified and recombinant human vitronectin readily form spherical oligomers and typical amyloid fibrils. Vitronectin oligomers are toxic to cultured neuroblastoma and retinal pigment epithelium (RPE) cells, possibly via a membrane-dependent mechanism, as they cause leakage of synthetic vesicles. Oligomer toxicity was attenuated in RPE cells by the anti-oligomer Al I antibody. Vitronectin fibrils contain a C-terminal protease-resistant fragment, which may approximate the core region of residues essential to amyloid formation.
\end{abstract}

Conclusion: These data reveal the propensity of vitronectin to behave as an amyloid protein and put forth the possibilities that accumulation of misfolded vitronectin may contribute to aggregate formation seen in age-related amyloid diseases.

\section{Background}

Vitronectin is a multi-functional glycoprotein involved in a variety of physiological processes. It is present in blood at a concentration of $0.2-0.45 \mathrm{mg} / \mathrm{ml}$, constituting $0.1-$
$0.5 \%$ of plasma protein, and is a component of the extracellular matrix $[1,2]$. While the liver is the primary site of vitronectin synthesis, several extrahepatic sites have been reported, including the retina [3-5], brain [6], and vascu- 
lar smooth muscle cells [7]. The multi-functional properties of vitronectin are mediated by its ability to interact with many other macromolecules. Vitronectin inhibits fibrinolysis through its N-terminal somatomedin B (SMB) domain, which binds to and stabilizes type 1 plasminogen activator inhibitor (PAI-1) [8,9]. Cell adhesion, spreading, and migration is promoted by the interaction of vitronectin's RGD sequence with several integrin receptors, including the $\alpha v \beta 3$ vitronectin receptor [10]. Vitronectin associates with components of the extracellular matrix via a collagen-binding domain and a polycationic heparin-binding domain $[11,12]$. The C-terminal heparin-binding domain also prevents complementmediated cell lysis by inhibiting assembly of the C5b-C9 membrane attack complex and blocking perforin pore formation [13-15].

Whilst its role in maintaining homeostasis has been studied extensively, the role of vitronectin in disease is not well understood, though it has been implicated in a number of disease processes. For example, vitronectin expression is upregulated in animal models of acute and chronic inflammation [16] and in fibrotic tissues $[17,18]$. In addition, serum levels of vitronectin are elevated in patients with atherosclerosis [19], type 2 diabetes [20], and Alzheimer disease (AD) [20]. Vitronectin has been identified in deposits associated with $\mathrm{AD}$, atherosclerosis, systemic amyloidoses, and glomerulonephritis [21-33]. In addition, we and others $[4,5,26,27,34-36]$ have observed vitronectin reactivity in all drusen samples analyzed, which are extracellular ocular deposits associated with aged eyes and eyes with age-related macular degeneration. Accumulation of vitronectin in extracellular deposits may be related to its proclivity to undergo structural rearrangements and its tendencies to self-associate and form multimers and high molecular aggregates in vitro, even under near physiological conditions [37-39]. The structural basis for the tendency of vitronectin to aggregate is incompletely understood. It has been observed that these insoluble vitronectin-containing disease deposits exhibit thioflavin staining [40-42], indicating an underlying process of protein misfolding and amyloid formation. In this study we address whether formation of amyloid structures may be a product of vitronectin misfolding. The investigation of vitronectin aggregation is significant since the formation of spherical and protofibrillar oligomers, as well as fibrils, are common properties of amyloid proteins, although they share neither sequence nor native structural homology. A growing body of evidence indicates that soluble prefibrillar oligomers may be the primary pathogenic species in amyloidopathies [43-47]. Thus, if vitronectin does indeed form amyloid oligomers or fibrils, its misfolding may contribute to the pathophysiology of the aforementioned diseases.
The development of the conformation-specific A11 antibody which recognizes soluble nonfibrillar oligomers made from a number of amyloidogenic peptides and proteins, but not monomers or fibrils, has aided the analysis of these toxic aggregates [48]. This antibody facilitates the characterization of soluble oligomers as markers of amyloid diseases and enables the identification of novel amyloid diseases wherein there is oligomer accumulation without abundant fibril deposition. One such disease is desmin-related cardiomyopathy $[49,50]$. We recently reported that human ocular drusen contain nonfibrillar oligomers, which suggests that age-related macular degeneration may be another example of this type of amyloidosis [35], and a number of studies identify vitronectin as one of the most abundant drusen proteins $[4,26,34,51]$. Vitronectin is an appealing candidate for misfolding due to its widespread distribution in the body and its association with insoluble, disease-associated plaques. In this study, we demonstrate that vitronectin behaves as an amyloid protein in vitro and soluble nonfibrillar vitronectin oligomers are toxic to cultured cells. Amyloidogenic propensity and toxicity suggest that vitronectin misfolding and aggregation may contribute to the pathophysiology of age-related diseases.

\section{Results \\ Vitronectin deposits in senile plaques of Alzheimer brain}

In order to assess the presence of vitronectin in extracellular deposits, we examined Alzheimer disease brain. In the senile plaques of $\mathrm{AD}$ brain, $\mathrm{A} \beta$ reactivity (Figure 1, upper panel, red) showed extensive overlap with the OC antibody (Figure 1 upper panel, green) which specifically recognizes amyloid fibrils and fibrillar oligomers. Lipofuscin autofluorescence is seen in the red channel together with $\mathrm{A} \beta$ but is not visible in the green channel. It can thus be distinguished by the red fluorescence. Similarly, robust vitronectin staining (Figure 1, lower panel, green) exhibited extensive overlap with $\mathrm{OC}$ reactivity in the plaques (Figure 1, lower panel, red). Overall, in the four cases of $\mathrm{AD}$ brain we examined there was a high correspondence of vitronectin reactivity in amyloid plaques, suggesting that vitronectin accumulates specifically in extracellular deposits that contain amyloid species.

\section{Vitronectin forms soluble nonfibrillar oligomers and amyloid fibrils}

To investigate whether vitronectin has an inherent propensity to behave as an amyloid protein, we aged plasmapurified and recombinant human vitronectin in phosphate-buffered saline (PBS). Plasma-purified and recombinant vitronectin in PBS form spherical and fibrillar structures by TEM (Figure 2, left). Because vitronectin in PBS produces a heterogeneous mixture of aggregates, we used 1,1,1,3,3,3-hexafluoro-2-propanol (HFIP), a commonly used solvent which enhances the rate of aggrega- 

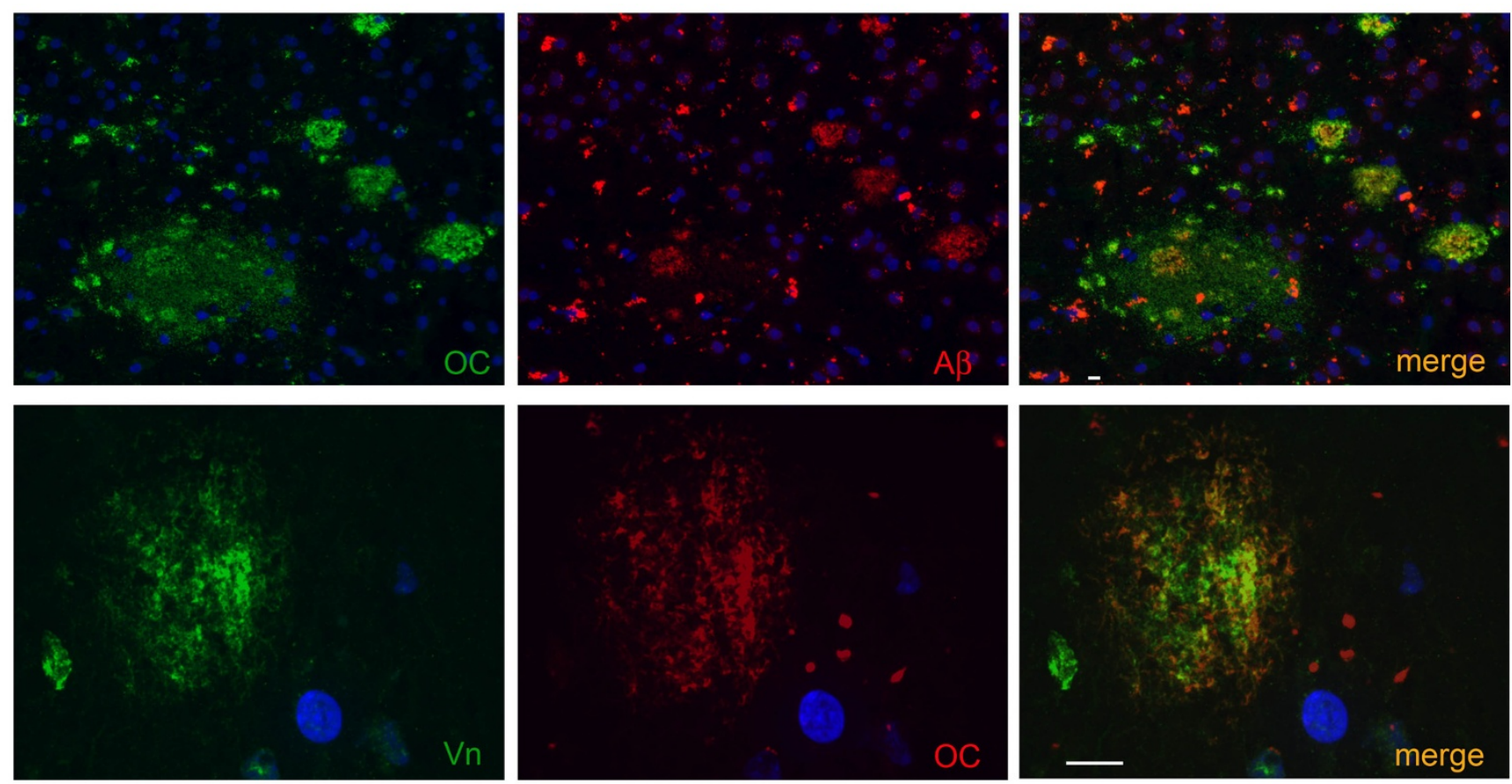

Figure I

Vitronectin deposits in senile plaques of Alzheimer disease brain. Upper panel: senile plaques of AD brain visualized with the $\mathrm{OC}$ antibody (green) and the 6EIO antibody against $A \beta$ (red). Lower panel: vitronectin (green) reactivity shows extensive overlap with $O C$ reactivity (red), suggesting that vitronectin is deposited at sites of amyloid formation. Co-localization appears as yellow-orange color, while lipofuscin autofluorescence is seen predominantly in the red channel. Nuclei were visualized with DAPI (blue). Scale bar $=10 \mu \mathrm{m}$.

tion [52,53], to enrich the fibril and oligomer populations. Treatment with 50\% HFIP promotes the formation of vitronectin fibrils, which resemble the morphology of typical amyloid fibrils (Figure 2, middle). The fibrils are approximately $3-8 \mathrm{~nm}$ in diameter, of varied length, and often twisted. Plasma-purified and recombinant vitronectin incubated in $20 \% \mathrm{HFIP}$ and $1 \mathrm{mM} \mathrm{HCl}$ adopt spherical and protofibrillar structures, which range in size from 6-35 $\mathrm{nm}$ in diameter (Figure 2, right). Both vitronectin oligomers and fibrils enhance thioflavin $\mathrm{T}$ fluorescence (data not shown).

\section{A I I-positive vitronectin oligomers are toxic to SH-SY5Y and RPE cells and induce membrane leakage}

To further characterize recombinant vitronectin oligomers, we performed a dot blot assay using the conformation-specific A11 antibody, which recognizes toxic oligomers formed by a variety of amyloidogenic proteins. Recombinant vitronectin freshly dissolved in phosphate buffer (Figure 3A) and vitronectin treated with 50\% HFIP to induce fibrils (Figure $3 \mathrm{C}$ ) are not recognized by the A11 antibody. However, recombinant vitronectin incubated in 20\% HFIP and $1 \mathrm{mM} \mathrm{HCl}$ exhibits A11 immunoreactivity (Figure 3B), suggesting that the population of soluble nonfibrillar oligomers is enriched under these conditions.
The quantity of vitronectin on the membrane was assessed using a primary anti-vitronectin antibody (Figure $3 \mathrm{~F}-\mathrm{I}$ ). $\mathrm{A} \beta$ oligomers (Figure $3 \mathrm{D}$ ) served as a positive control for the A11 antibody, but were not recognized by the vitronectin antibody, as expected (Figure 3H).

Recent evidence suggests soluble nonfibrillar oligomers may comprise a toxic species. Because A11 immunoreactivity has been reported to correlate with cytotoxicity and recombinant vitronectin oligomers are A11-positive, we examined their effects on cultured SH-SY5Y and retinal pigment epithelium (RPE) cells. SH-SY5Y neuroblastoma cells and RPE cells were chosen due to the emerging role of soluble oligomers as pathogenic entities in neurodegenerative diseases such as Alzheimer disease and agerelated macular degeneration. HFIP was removed by evaporation and indicated concentrations of recombinant vitronectin oligomers diluted in serum-free DMEM were added to cells for 4 hours at $37^{\circ} \mathrm{C}$. Cell viability was assessed spectrophotometrically using an MTT-based assay. Vitronectin oligomers were toxic to both SH-SY5Y and RPE cells in a dose-dependent manner, as observed by impaired MTT reduction (Figure 4, white and grey bars). Plasma-purified and recombinant vitronectin aged in PBS exhibited mild RPE toxicity (Figure 4, hatched bars). Pre- 



\section{Figure 2}

Human vitronectin forms amyloid fibrils and oligomers. Left, Plasma-purified $(\mathrm{hVn})$ and recombinant human vitronectin $(r V n)$ aged in phosphate-buffered saline form a heterogeneous mixture of spherical and fibrillar structures as seen under TEM. Middle, Vitronectin treated with $50 \%$ HFIP promotes the formation of typical amyloid fibrils that are approximately 3-8 nm in diameter. Right, Incubation in $20 \%$ HFIP and I $\mathrm{mM} \mathrm{HCl}$ enriches the population of spherical and protofibrillar oligomers, which range from $6-35 \mathrm{~nm}$ in diameter. Scale bar $=100 \mathrm{~nm}$.

incubation of $5 \mu \mathrm{M}$ recombinant vitronectin oligomers with an equimolar amount of A11 antibody prior to treatment significantly attenuated the impairment in MTT reduction, indicating oligomer-specific toxicity (Figure 4, black bar) and demonstrating the ability of the A11 antibody to block the majority of toxic oligomeric species.

It has been suggested that the plasma membrane is a common target of toxic nonfibrillar oligomers. To investigate the hypothesis that vitronectin oligomers disrupt membrane integrity, we employed a fluorescence-based leakage assay using large unilamellar vesicles (LUVs) of 100 nm diameter loaded with the fluorophore-quencher pair ANTS-DPX. Indicated concentrations of freshly-dissolved recombinant vitronectin or recombinant vitronectin oligomers were diluted in Buffer 1 (see Materials and Methods) containing $500 \mu \mathrm{M}$ lipids. ANTS fluorescence was monitored over time at $520 \mathrm{~nm}\left(\lambda_{\text {ex }}=353 \mathrm{~nm}\right)$ and per- cent leakage was estimated by dividing the sample and maximum fluorescence intensity values after correcting for the intrinsic fluorescence of the vesicles. Freshly-dissolved recombinant vitronectin had no appreciable effect on membrane permeability (Figure 5, white bars). Vitronectin oligomers induced dose-dependent leakage of ANTS from LUVs (Figure 5, grey bars), indicating that membrane disruption is caused by the oligomeric conformation.

\section{Trypsin digestion of vitronectin fibrils reveals a protease- resistant core}

To facilitate the isolation and identification of the amyloidogenic core of vitronectin fibrils, we employed protease digestion followed by peptide sequencing, immunoblotting, and mass spectrometry analysis. Undigested vitronectin fibrils are shown in Figure 6A (lane 1). It is evident that a large amount of aggregated protein was 


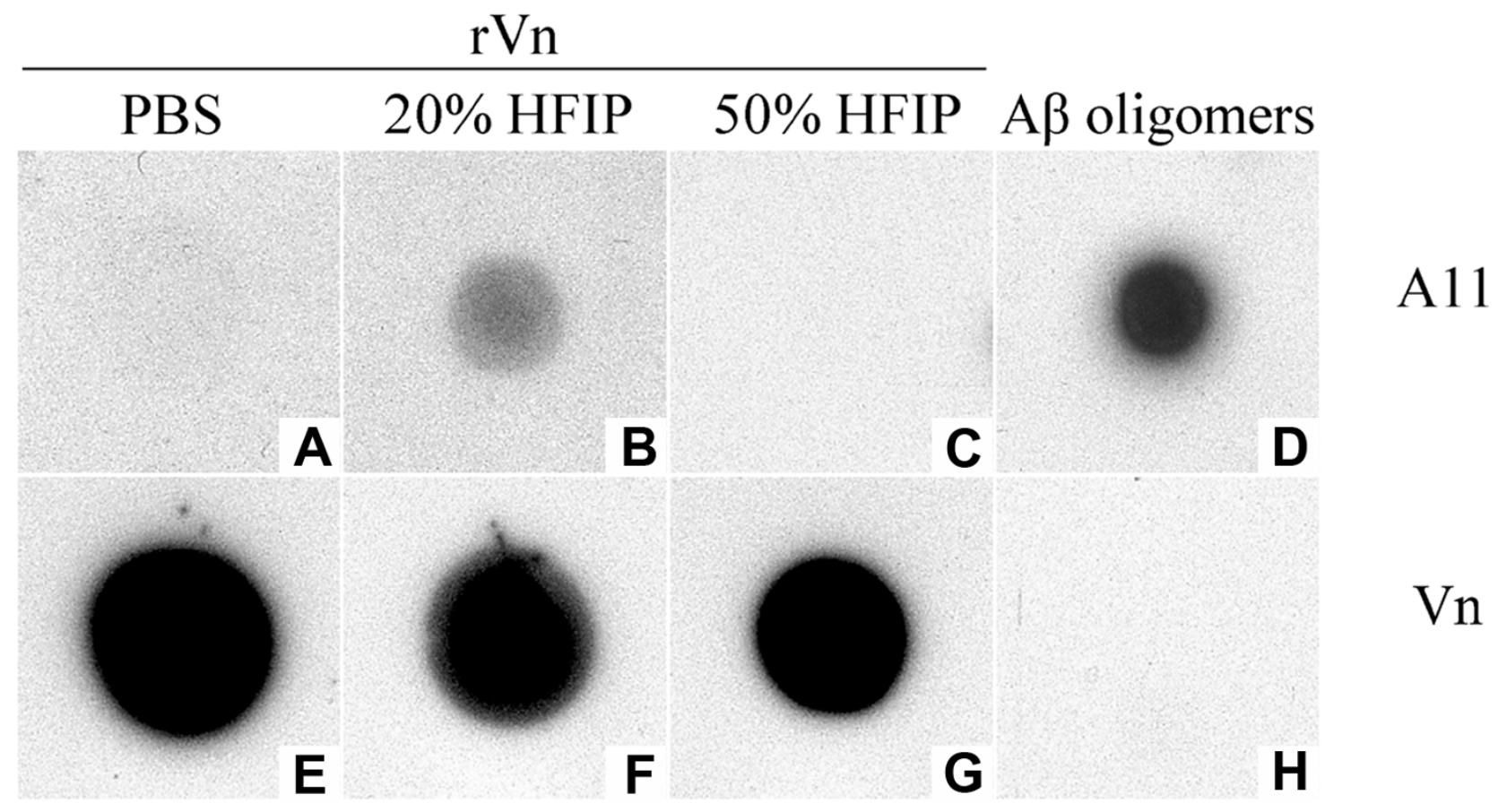

Figure 3

Vitronectin forms soluble nonfibrillar amyloid oligomers. Samples were spotted on a nitrocellulose membrane and probed with either AII (A-D) or vitronectin (E-H) primary antibodies. Recombinant vitronectin (rVn) incubated in $20 \% \mathrm{HFIP}$ and I $\mathrm{mM} \mathrm{HCl}$ exhibits reactivity to the oligomer-specific AII antibody (B), whereas vitronectin freshly dissolved in phosphate buffer (A) or treated with $50 \%$ HFIP (C) do not, suggesting that treatment with $20 \%$ HFIP enriches the population of soluble oligomers. Reactivity of samples with the vitronectin antibody confirms the presence of protein (E-G). A $\beta$ oligomers served as a positive control for the AII antibody (D), but are not detected by the vitronectin antibody $(H)$.

not resolved by SDS-PAGE and was retained in the wells or did not pick up the Coomassie stain (Figure 6A, asterisk). Trypsin digestion of vitronectin fibrils produced a major protease-resistant fragment of $\sim 5 \mathrm{kDa}$ (Figure 6A, lane 2). This band was not present when soluble recombinant vitronectin was digested (data not shown). Partial protein sequencing of the first twenty-one amino acids by N-terminal Edman degradation identified the peptide AMWLSLFSSEESNLGANNYDD in the excised band, which comprises C-terminal residues 380-400. The origin of the peptide was confirmed by western blot with a C-terminal-specific vitronectin antibody (data not shown). MALDI-TOF mass spectrometry analysis of the excised fragment identified several vitronectin peptides (Figure 6B) and suggests that residues 380-427 may be important for amyloid formation. The peptides correlate well with Cterminal stretches of increased cross-beta aggregation propensity as predicted by the TANGO algorithm (Figure 6B).

\section{Discussion}

In this study, we demonstrate that in the AD brain, vitronectin and the fibril-specific OC antibody showed extensive overlap within senile plaques, suggesting that vitronectin may participate in amyloid formation at those sites. Importantly, we provide evidence that vitronectin is capable of amyloid formation. Consistent with previous reports [37-39], we observed that vitronectin readily forms aggregates, even in physiologic buffer. In this study we demonstrate that such aggregates display amyloid structures. These results extend previous in vitro studies of vitronectin aggregation and provide a possible structural basis for such oligomerization. HFIP treatment, although not required, enriched the individual populations of soluble, spherical oligomers and amyloid fibrils. Our results establish the amyloidogenicity of vitronectin and are in agreement with previously published reports regarding the toxicity of soluble oligomers [54]. The finding that HFIP treatment enhances oligomer and fibril formation supports the hypothesis that partial unfolding or denatur- 


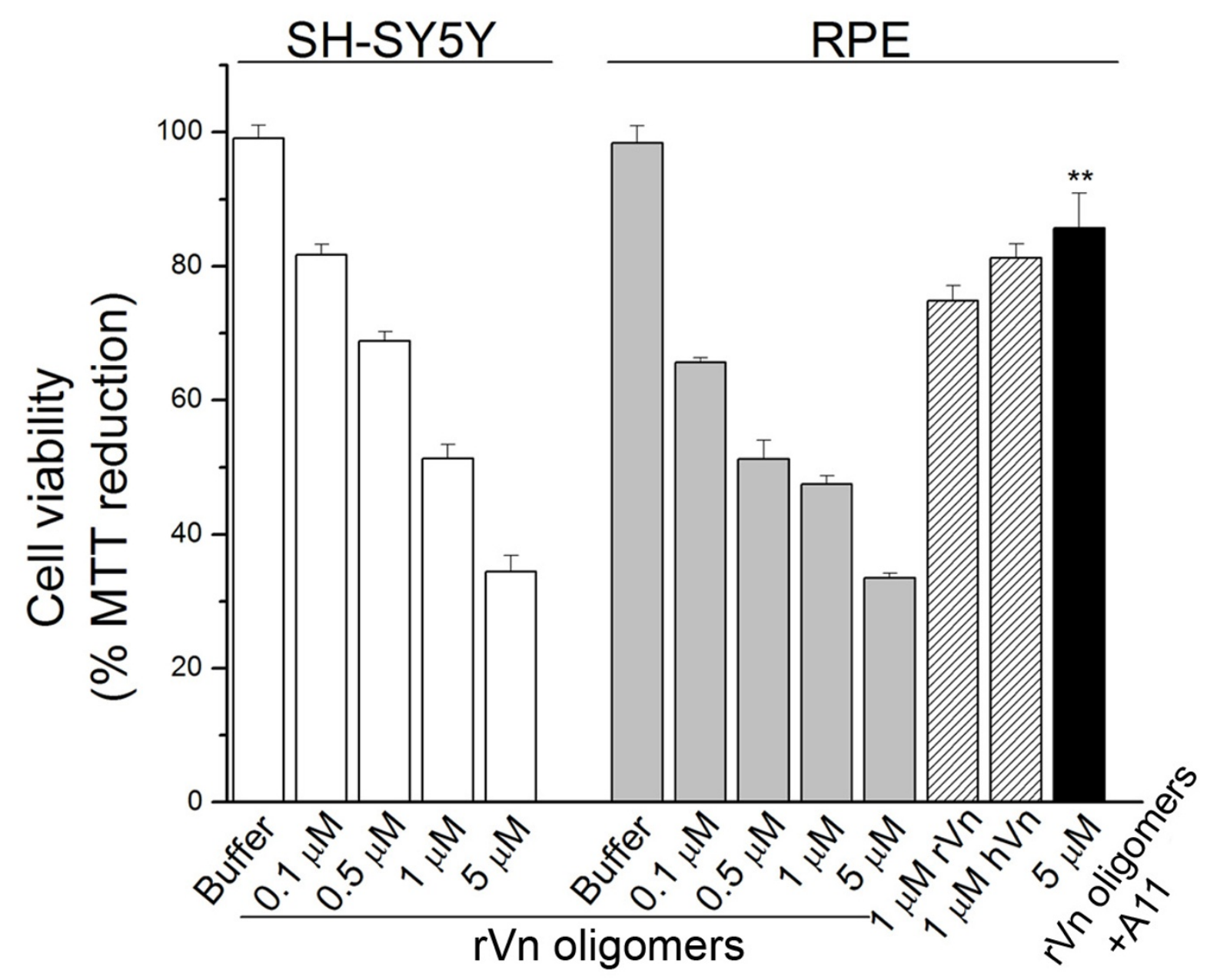

Figure 4

Soluble nonfibrillar vitronectin oligomers compromise cell viability. Recombinant vitronectin ( $r V n$ ) oligomers are toxic to SH-SH5Y (white bars) and RPE cells (grey bars) in a dose-dependent manner, as evidenced by impaired MTT reduction. Plasma-purified $(\mathrm{hVn})$ and recombinant vitronectin aged in PBS exhibit mild toxicity (hatched bars). RPE toxicity was significantly attenuated when $5 \mu \mathrm{M}$ recombinant vitronectin oligomers were pre-incubated with an equimolar amount of $\mathrm{AII}$ antibody prior to treatment (black bar), although complete rescue was not observed. Cell viability was assessed spectrophotometrically using an MTT-based assay. Error bars represent standard error of the mean. $\left(n=3 ; *^{*} p<0.0 \mathrm{I}\right)$.

ation of the native protein state promotes misfolding and subsequent formation of amyloid structures [55]. Vitronectin is known to accumulate in extracellular deposits in the eye and brain that are associated with macular degeneration and Alzheimer disease, respectively $[4,21,24,27,33]$. Interestingly, vitronectin oligomers recognized by the conformation-specific A11 antibody are cytotoxic to cultured RPE and SH-SY5Y cells in a dosedependent manner. Soluble oligomers formed in vitro from a variety of proteins appear morphologically similar and exhibit toxicity to cultured cells [48,54,56-63], suggesting a common pathogenic mechanism. Pre-incubation of vitronectin oligomers with the A11 antibody prior to treatment significantly rescued RPE cell viability, demonstrating that the majority of toxic nonfibrillar oligomers are neutralized by the A11 antibody. Vitronectin oligomers permeabilize synthetic vesicles in a cell-free 


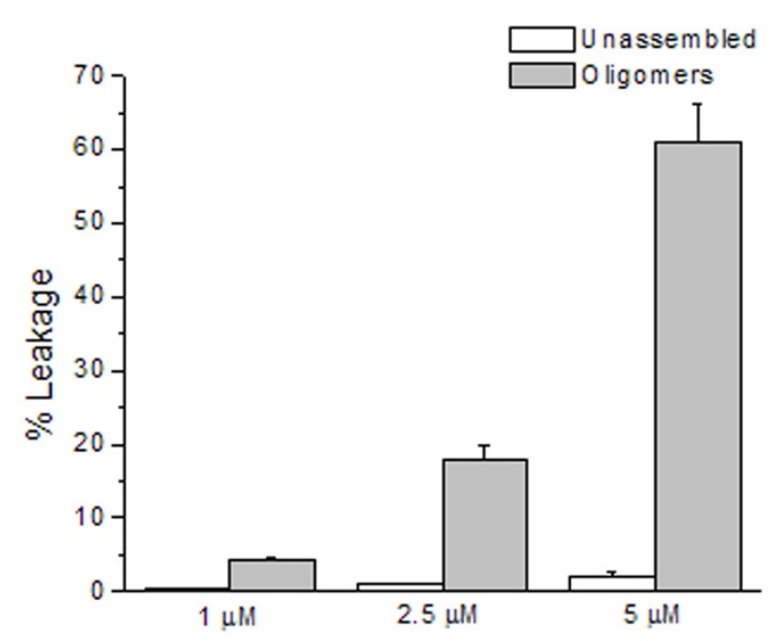

\section{Figure 5}

Vitronectin oligomers induce membrane leakage. Large unilamellar vesicles (100 nm in diameter) loaded with the fluorophore-quencher pair ANTS-DPX were incubated with indicated concentrations of protein. Recombinant vitronectin oligomers incubated with $500 \mu \mathrm{M}$ LUVs resulted in appreciable leakage of vesicles in a dose-dependent fashion (grey bars) as compared to recombinant vitronectin freshly dissolved in phosphate buffer (white bars). Membrane leakage was assessed by monitoring ANTS fluorescence $\left(\lambda_{\text {ex }}=\right.$ $353 \mathrm{~nm}, \lambda_{\mathrm{em}}=520 \mathrm{~nm}$ ). Intensities were normalized to the intrinsic fluorescence of the vesicles and percent leakage was estimated by dividing the sample and maximum fluorescence intensity values. Data shown are the combined average of three independent experiments. Error bars represent the standard error of the mean.

assay, which is consistent with studies showing that soluble amyloid oligomers disrupt membranes [52,62,64-67].

Vitronectin fibrils resemble the morphology of typical amyloid fibrils and contain a protease-resistant domain which likely contains the core residues sufficient for amyloid formation. The trypsin-resistant band was seen by SDS-PAGE and Coomassie stain when vitronectin fibrils were digested, but not when soluble recombinant vitronectin was digested. Sequencing and immunoblotting of the fragment revealed a C-terminal epitope and mass spectrometry analysis identified several peptides within residues 380-427, indicating that this region may be important for amyloid formation. Interestingly, the identified fragments overlap with two C-terminal regions that have increased cross-beta aggregation propensity, as calculated by the TANGO algorithm [68]. This region has been predicted to have a beta-propeller like domain in solution [69]. The combined data from mass spectrometry and TANGO analysis suggest the existence of an ordered amyloid core which limits protease accessibility to the stretch of amino acids between the two predicted aggregation-prone regions. The putative amyloid core resides within a naturally-occurring $10 \mathrm{kDa}$ fragment (residues 380-459). Primary sequence analysis of the $10 \mathrm{kDa}$ vitronectin fragment reveals a stretch of highly hydrophobic amino acids, which is consistent with the hypothesis that hydrophobicity is a key factor in aggregation propensity [55,68,70-72]. Further studies are warranted to precisely delineate the boundaries of the vitronectin amyloidogenic core and to characterize the in vitro and in vivo significance of the $10 \mathrm{kDa}$ vitronectin fragment.

Vitronectin exists in two distinct conformations in vivo. The majority of vitronectin in plasma and serum circulates as a non-heparin-binding monomer. Approximately 2$8 \%$ of vitronectin in the blood is in the alternate heparinbinding, partially unfolded conformation which can selfassociate [73]. This multimeric form is thought to be the predominant conformation of vitronectin in the extracellular matrix [74]. Chaotropic denaturation, which was used in the purification of recombinant vitronectin, exposes the heparin-binding site [37]. Since vitronectin readily aggregates in its heparin-binding state, this specific conformation may aid in amyloid formation, a hypothesis further supported by the observation that hydrophobic interactions appear to drive functional oligomerization [75]. Interestingly, the protease-resistant region is located adjacent to the heparin-binding domain.

\section{Conclusion}

Although a relatively small percentage of vitronectin is in an alternate conformation, conditions of high local concentration via increased synthesis or recruitment, which may occur at extravascular sites or in the setting of chronic inflammation, may promote vitronectin misfolding and amyloid formation. Our results put forth the possibility that vitronectin misfolding and amyloid formation may contribute to age-related diseases such as atherosclerosis, $\mathrm{AMD}$, and $\mathrm{AD}$.

\section{Methods \\ Antibodies and reagents}

Plasma-purified vitronectin was purchased from Biosource (Camarillo, CA). The 6E10 antibody against betaamyloid (A $\beta$ ) 1-16 was purchased from Covance Research Products, Inc. (Dedham, MA). The anti-oligomer A11 antibody and OC antisera were generated as previously described $[48,76]$. Production of a polyclonal antivitronectin antibody raised against full-length recombinant vitronectin was performed by Biomer Technology (Hayward, CA). The IgG fraction was enriched from rabbit serum using Affi-Gel Protein A support (Bio-Rad; Hercules, CA). Secondary antibodies were purchased from Vector Laboratories (Burlingame, CA). All other reagents 
A

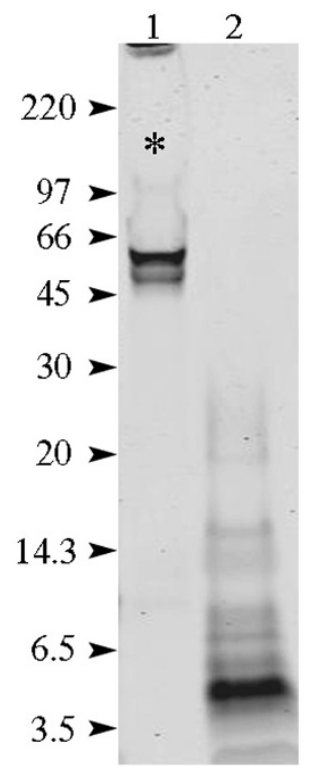

B

\begin{tabular}{|c|l|c|}
\hline$\underline{\mathbf{m} / \mathbf{z}}$ & \multicolumn{1}{|c|}{$\underline{\text { Sequence }}$} & $\underline{\text { Residue \# }}$ \\
\hline 2683.03 & AMWLSLFSSEESNLGANNYDDYR & A380-R402 \\
\hline $5740.14,5751.87$ & $\begin{array}{l}\text { AMWLSLFSSEESNLGANNYDDYRM } \\
\text { DWLVPATCEPIQSVFFFSGDKYYR }\end{array}$ & A380-R427 \\
\hline
\end{tabular}

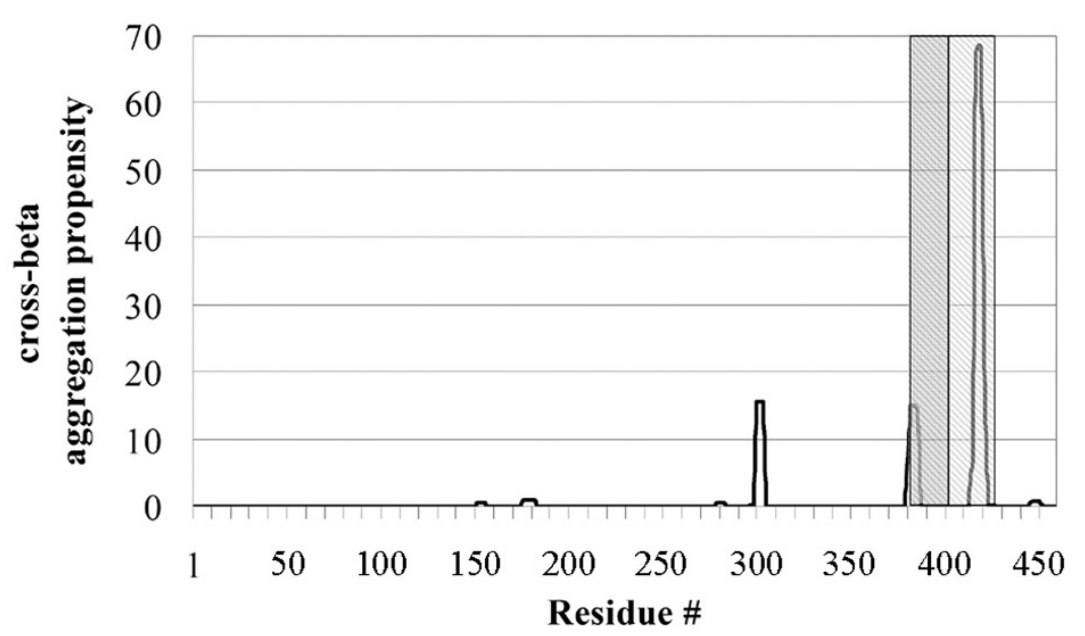

Figure 6

Vitronectin fibrils contain a protease-resistant core. A) In-solution trypsin digestion of vitronectin fibrils reveals a protease-resistant band of $\sim 5 \mathrm{kDa}$ (lane 2). Partial sequencing by $\mathrm{N}$-terminal Edman degradation identified the peptide AMWLSLFSSEESNLGANNYDD, which corresponds to residues 380-400. These amino acids reside in the C-terminus of the protein and likely comprise a portion the amyloidogenic core. This result was confirmed by immunoblotting with a C-terminal-specific antibody (data not shown). Arrowheads indicate molecular weight $(\mathrm{kDa})$. Lane I contains undigested vitronectin fibrils, much of which is unresolved (asterisk). B) Upper panel: Several peptides were identified by MALDI-TOF analysis of the protease-resistant band. The mass/charge $(\mathrm{m} / \mathrm{z}$ ) values, amino acid sequence and residue numbers are displayed in the table. Each $\mathrm{m} / \mathrm{z}$ does not correspond to any other vitronectin peptides and oxidation had to be invoked for peptide A380-R427. Lower panel: Primary sequence analysis of vitronectin using the TANGO algorithm [68] reveals several C-terminal stretches prone to crossbeta aggregation, two of which correlate well with the peptides A380-R402 (gray) and A380-R427 (hatched) identified by mass spectrometry. $\mathrm{Y}$-axis denotes relative cross-beta aggregation propensity.

were purchased from Sigma-Aldrich (St. Louis, MO), unless otherwise specified.

\section{Immunocytochemistry}

Frozen human cortex was obtained from the USC Alzheimer Disease Research Center. Intact human eyes were obtained from the Oregon Lions Sight and Hearing Foundation. Tissue was prepared as described previously [35]. Briefly, sections were blocked overnight in phosphatebuffered saline containing 2\% BSA and 2\% goat serum, followed by incubation with either the anti-vitronectin antibody or OC antisera. Sections were washed and incubated with either FITC- or Texas Red-conjugated goat antirabbit antibody. DAPI was used to visualize nuclei. Images were acquired on an UltraVIEW VoX spinning disk confocal microscope (PerkinElmer, Waltham, Massachusetts).

\section{Cloning, expression, and purification of full-length human vitronectin}

A plasmid containing human vitronectin cDNA was purchased from American Tissue Culture Company (ATCC; Rockville, MD) and a 1,385 bp fragment of mature, fulllength human vitronectin cDNA containing engineered $\mathrm{N}$-terminal NcoI and C-terminal HindIII restriction sites was synthesized by polymerase chain reaction. The fragment was digested with $\mathrm{NcoI}$ and HindIII restriction enzymes (New England Biolabs; Ipswich, MA) and subcloned into a pSE420 vector with complementary sticky ends. Correct orientation of the insert was verified by DNA sequencing and Escherichia coli DH5 $\alpha$ cells were 
transformed with the $4.27 \mathrm{~kb}$ construct. Cells were grown with shaking at $37^{\circ} \mathrm{C}$ to an optical density of $0.6-0.8$ and protein expression was induced by the addition of $1 \mathrm{mM}$ isopropyl-1-thio- $\beta$-D-galactopyranoside (IPTG) for 4 hours at $37^{\circ} \mathrm{C}$. Cells were harvested by centrifugation at $5,000 \times \mathrm{g}$ for 15 minutes and the pellet was stored at $80^{\circ} \mathrm{C}$. Vitronectin protein was purified using a previously described protocol [77] with modifications. The pellet was resuspended in lysis buffer [5 mM EDTA, $10 \mathrm{mM}$ dithiothreitol (DTT), $1 \mathrm{mg} / \mathrm{mL}$ lysozyme, protease inhibitors, all in $10 \mathrm{mM}$ sodium phosphate buffer, $\mathrm{pH} 7.4$ ], incubated on ice for 1 hour, then nutated at $4^{\circ} \mathrm{C}$ for 10 minutes with the addition of $24 \mathrm{U} / \mathrm{ml}$ DNase I, $60 \mathrm{mM}$ $\mathrm{MgCl}_{2}$, and $1 \%$ Triton $\mathrm{X}-100$. The suspension was sonicated $3 \times 1$ minute on ice, with one minute between sonications, and centrifuged at 20,000 $\times g$ for 30 minutes. The pellet was resuspended in $2 \mathrm{M}$ urea buffer ( $2 \mathrm{M}$ urea, 5 mM EDTA, $10 \mathrm{mM}$ DTT, protease inhibitors, all in $10 \mathrm{mM}$ sodium phosphate buffer, $\mathrm{pH} 7.4$ ), sonicated on ice, centrifuged, and supernatant decanted. The resulting pellet of inclusion bodies was solubilized in cold $8 \mathrm{M}$ urea buffer (8 $\mathrm{M}$ urea, $5 \mathrm{mM}$ EDTA, $10 \mathrm{mM}$ DTT, protease inhibitors, all in $10 \mathrm{mM}$ sodium phosphate buffer, $\mathrm{pH} 7.4$ ), sonicated on ice, and centrifuged. The supernatant was applied to a HiTrap heparin affinity column (Amersham Biosciences; Piscataway, NJ) equilibrated with $8 \mathrm{M}$ urea buffer and proteins were eluted using a linear $\mathrm{NaCl}$ gradient. Vitronectin-containing fractions were identified by SDS-PAGE, pooled, and dialyzed against $1 \%$ acetic acid, $10 \mathrm{mM}$ phosphate buffer (pH 7.4), or PBS. Protein purity was $>95 \%$ by Coomassie Blue staining. Protein concentration was calculated from absorbance at $280 \mathrm{~nm}\left(\varepsilon_{\mathrm{M}}=\right.$ $\left.82,330 \mathrm{M}^{-1} \mathrm{~cm}^{-1}\right)$.

\section{Fibril and oligomer preparation}

Lyophilized vitronectin protein in a siliconized microcentrifuge tube was dissolved in cold 1,1,1,3,3,3-hexafluoro2-propanol (HFIP) for 10 minutes at room temperature. For fibrils, this solution was diluted to 50\% HFIP in water and stirred at room temperature for 7-14 days at a protein concentration of 10-25 $\mu \mathrm{M}$. Fibril formation was monitored by transmission electron microscopy (TEM). To prepare soluble oligomers, vitronectin in HFIP was diluted to $20 \% \mathrm{HFIP}$ and $1 \mathrm{mM} \mathrm{HCl}$ and stirred at room temperature with a vented lid for 3-7 days. The final protein concentration was approximately $20 \mu \mathrm{M}$ after the gradual evaporation of HFIP. Oligomer formation was monitored by TEM and by dot blot using the anti-oligomer antibody. Alternatively, lyophilized vitronectin was resuspended in PBS and aged for 2-4 weeks at room temperature with or without stirring to form oligomers and fibrils without HFIP.

\section{Electron microscopy}

HFIP was evaporated under a gentle stream of nitrogen. Ten microliters of sample was applied to a 200-mesh formvar-coated nickel grid (Electron Microscopy Sciences; Hatfield, PA) for 5 minutes, stained in 3\% uranyl acetate for 5 minutes, rinsed, and air-dried. The grids were examined using a Jeol JEM1200EX microscope at $80 \mathrm{kV}$.

\section{Dot blot}

Two microliters of each sample were spotted onto nitrocellulose membrane and allowed to air-dry. Tris-buffered saline $(20 \mathrm{mM}$ Tris, $0.8 \% \mathrm{NaCl}, \mathrm{pH} 7.4)$ containing $0.001 \%$ Tween-20 (TBST) was used for washing and dilution. The membrane was blocked for 1 hour with $10 \%$ nonfat dried milk in TBST, washed $3 \times 10$ minutes, incubated for one hour in primary anti-oligomer antibody (1:5,000 in 3\% BSA/TBST), washed $3 \times 10$ minutes, incubated for 30 minutes in HRP-conjugated secondary antirabbit antibody (1:10,000 in 3\% BSA/TBST), and washed $3 \times 10$ minutes. The membrane was developed using enhanced chemiluminescence reagents (Amersham Biosciences; Piscataway, NJ) and exposed to Hyperfilm (Amersham Biosciences; Piscataway, NJ). The same procedure was performed for dot blot with anti-vitronectin antibody (1:10,000; Biomer Technology, Hayward, CA) using $0.1 \%$ Tween-20 in TBST. A control membrane with primary antibody omitted was simultaneously processed.

\section{Cell culture}

SH-SY5Y cells were obtained from ATCC (Rockville, MD). Retinal pigment epithelium (RPE) cells were isolated from human fetal eyes obtained from Advanced Bioscience Resources, Inc. (Alameda, CA) as described previously [78]. Cells were maintained in complete medium [Dulbecco's modified Eagle's medium (DMEM, VWR; West Chester, PA) supplemented with $2 \mathrm{mM}$ L-glutamine, 100 $\mathrm{U} / \mathrm{ml}$ penicillin, $100 \mu \mathrm{g} / \mathrm{ml}$ streptomycin, and $10 \%$ fetal bovine serum (Invitrogen; Carlsbad, CA)] at $37^{\circ} \mathrm{C}$ in a humidified incubator. Fourth-passage cells were seeded in a 96-well plate at $2 \times 10^{4}$ cells per well and grown in complete medium for 3-4 days to approximately $90 \%$ confluence. Cells were maintained in serum-free medium for one day prior to the experiment. On the day of the assay, media was removed, replaced with the indicated samples diluted in DMEM, and incubated at $37^{\circ} \mathrm{C}$ for 4 hours. MTT (3-[4, 5-dimethylthiazol-2-yl]-2, 5-diphenyl tetrazolium bromide) dissolved in DMEM was added and cells were placed at $37^{\circ} \mathrm{C}$ for an additional 4 hours. Tetrazolium crystals were dissolved by the addition of MTT solubilization solution $(10 \%$ Triton X-100, $0.1 \mathrm{~N} \mathrm{HCl}$ in anhydrous isopropanol), and absorbance was measured at $570 \mathrm{~nm}$. Experiments were carried out in triplicates. 


\section{Membrane leakage}

Large unilamellar vesicles (LUVs, $100 \mathrm{~nm}$ diameter) containing $90 \%$ phosphatidylcholine and $10 \%$ phosphatidylserine (Avanti Polar Lipids; Alabaster, AL) were extruded in the presence of the fluorophore-quencher pair 8-aminonaphthalene-1,3,6-trisulfonic acid (ANTS) and pxylene-bis-pyridinium bromide (DPX). To assess membrane leakage, a $250 \mu \mathrm{l}$ solution containing $500 \mu \mathrm{M}$ LUVs and the sample of interest in Buffer 1 (10 mM HEPES, 50 $\mathrm{mM} \mathrm{KCl}, 1 \mathrm{mM}$ EDTA, $3 \mathrm{mM}$ sodium azide) was placed in a $2 \mathrm{~mm}$ path-length quartz cuvette. ANTS fluorescence was monitored as a function of time at $520 \mathrm{~nm}$ with excitation at $353 \mathrm{~nm}$ using a Jasco FP-6500 spectrofluorimeter. Maximum fluorescence intensity was determined by adding $5 \mu \mathrm{l}$ of $10 \%$ Triton X-100. Intensities were normalized to the intrinsic fluorescence of the vesicles and percent leakage was estimated by dividing the sample and maximum fluorescence intensity values. The data represent the results of three independent experiments.

\section{Protease digestion}

Fibrils were collected by centrifugation and the pellets were digested in a solution containing 1:25 trypsin (protease-to-protein mass ratio) and $10 \mathrm{mM}$ DTT, all in 50 $\mathrm{mM}$ ammonium bicarbonate, $\mathrm{pH} 8$, at $37^{\circ} \mathrm{C}$. Overnight digests were heat inactivated at $60^{\circ} \mathrm{C}$, analyzed by SDSPAGE, and visualized with Coomassie Blue staining. The major protease-resistant fragment was either transferred onto a PVDF membrane and submitted to the USC/Norris Microchemical Core Facility for peptide sequencing by Nterminal Edman degradation, or excised and passively eluted in $50 \mathrm{mM}$ Tris, $50 \mathrm{mM} \mathrm{NaCl}(\mathrm{pH} 8)$ and submitted to the USC Proteomics Core Facility for matrix-assisted laser desorption/ionization time-of-flight (MALDI-TOF) mass spectrometry analysis.

\section{Competing interests}

CG and RK are paid consultants for Kinexis, Inc.

\section{Authors' contributions}

TMS carried out the molecular cloning, protein purification, preparation of fibrils and oligomers, dot blot, cell culture and toxicity assays, protease digestion, mass spectrometry, data analysis, and drafted the manuscript. JMI participated in the electron microscopy, mass spectrometry, immunocytochemistry on human AD tissue, and data analysis. $\mathrm{CH}$ performed the immunocytochemistry on human $\mathrm{AD}$ tissue. RK and CGG developed and characterized the OC and A11 antibodies. RL and JC participated in concept, design, data analysis and manuscript preparation. All authors read and approved the final manuscript.

\section{Acknowledgements}

This work was supported by National Aging Institute in the form of an Alzheimer disease research center (NIA AG05 I42), the National Eye Institute in the form of a Vision Core Grant to Doheny Eye Institute (EY03040), a network grant from the Larry L. Hillblom Foundation (C.G., J.C. and R.L.), and a Medical Student Research Fellowship from Research to Prevent Blindness (to T.M.S. and J.C.).

\section{References}

I. Preissner KT: Structure and biological role of vitronectin. Annu Rev Cell Biol I99I, 7:275-310.

2. Schvartz I, Seger D, Shaltiel S: Vitronectin. Int J Biochem Cell Biol 1999, 3 |:539-544.

3. Anderson DH, Hageman GS, Mullins RF, Neitz M, Neitz J, Ozaki S, Preissner KT, Johnson LV: Vitronectin gene expression in the adult human retina. Invest Ophthalmol Vis Sci 1999, 40:3305-33I5.

4. Hageman GS, Mullins RF, Russell SR, Johnson LV, Anderson DH: Vitronectin is a constituent of ocular drusen and the vitronectin gene is expressed in human retinal pigmented epithelial cells. Faseb J 1999, I 3:477-484.

5. Ozaki S, Johnson LV, Mullins RF, Hageman GS, Anderson DH: The human retina and retinal pigment epithelium are abundant sources of vitronectin mRNA. Biochem Biophys Res Commun 1999, 258:524-529.

6. Walker DG, McGeer PL: Vitronectin expression in Purkinje cells in the human cerebellum. Neurosci Lett I998, 25 I:I09-I I2.

7. Dufourcq P, Louis H, Moreau C, Daret D, Boisseau MR, Lamaziere $J M$, Bonnet J: Vitronectin expression and interaction with receptors in smooth muscle cells from human atheromatous plaque. Arterioscler Thromb Vasc Biol 1998, I 8:168-I76.

8. Declerck PJ, De Mol M, Alessi MC, Baudner S, Paques EP, Preissner KT, Muller-Berghaus G, Collen D: Purification and characterization of a plasminogen activator inhibitor I binding protein from human plasma. Identification as a multimeric form of $S$ protein (vitronectin). J Biol Chem 1988, 263: I5454-I546I.

9. Keijer J, Ehrlich HJ, Linders M, Preissner KT, Pannekoek H: Vitronectin governs the interaction between plasminogen activator inhibitor I and tissue-type plasminogen activator. J Biol Chem 1991, 266:10700-10707.

10. Cherny RC, Honan MA, Thiagarajan P: Site-directed mutagenesis of the arginine-glycine-aspartic acid in vitronectin abolishes cell adhesion. J Biol Chem 1993, 268:9725-9729.

II. Gebb C, Hayman EG, Engvall E, Ruoslahti E: Interaction of vitronectin with collagen. J Biol Chem 1986, 26 I: I6698-16703.

12. Ishikawa-Sakurai M, Hayashi M: Two collagen-binding domains of vitronectin. Cell Struct Funct 1993, I 8:253-259.

13. Biesecker G: The complement SC5b-9 complex mediates cell adhesion through a vitronectin receptor. J Immunol 1990, | 45:209-2|4.

14. Milis L, Morris CA, Sheehan MC, Charlesworth JA, Pussell BA: Vitronectin-mediated inhibition of complement: evidence for different binding sites for C5b-7 and C9. Clin Exp Immunol 1993, 92:114-119.

15. Su HR: S-protein/vitronectin interaction with the $\mathbf{C 5 b}$ and the C8 of the complement membrane attack complex. Int Arch Allergy Immunol 1996, I I 0:3 I4-317.

16. Seiffert D, Geisterfer M, Gauldie J, Young E, Podor TJ: IL-6 stimulates vitronectin gene expression in vivo. J Immunol 1995, I55:3180-3185.

17. Kobayashi J, Yamada S, Kawasaki H: Distribution of vitronectin in plasma and liver tissue: relationship to chronic liver disease. Hepatology 1994, 20:1412-1417.

18. Reilly JT, Nash JR: Vitronectin (serum spreading factor): its localisation in normal and fibrotic tissue. J Clin Pathol 1988, 4 I : I 269- I 272.

19. Ekmekci H, Sonmez H, Ekmekci OB, Ozturk Z, Domanic N, Kokoglu $\mathrm{E}$ : Plasma vitronectin levels in patients with coronary atherosclerosis are increased and correlate with extent of disease. J Thromb Thrombolysis 2002, I 4:221-225.

20. Zhang R, Barker L, Pinchev D, Marshall J, Rasamoelisolo M, Smith C, Kupchak P, Kireeva I, Ingratta L, Jackowski G: Mining biomarkers in human sera using proteomic tools. Proteomics 2004, 4:244-256.

21. Akiyama H, Kawamata T, Dedhar S, McGeer PL: Immunohistochemical localization of vitronectin, its receptor and beta-3 integrin in Alzheimer brain tissue. J Neuroimmunol 1991, 32:19-28. 
22. Dahlback K, Lofberg H, Dahlback B: Immunohistochemical demonstration of vitronectin in association with elastin and amyloid deposits in human kidney. Histochemistry 1987, 87:5 I I-5 I5.

23. Dahlback K, Lofberg H, Dahlback B: Immunohistochemical studies on vitronectin in elastic tissue disorders, cutaneous amyloidosis, lichen ruber planus and porphyria. Acta Derm Venereol 1988, 68: 107-|| 5 .

24. Eikelenboom $P$, Zhan SS, Kamphorst W, Valk $P$ van der, Rozemuller JM: Cellular and substrate adhesion molecules (integrins) and their ligands in cerebral amyloid plaques in Alzheimer's disease. Virchows Arch 1994, 424:421-427.

25. Guettier C, Hinglais N, Bruneval P, Kazatchkine M, Bariety J, Camilleri JP: Immunohistochemical localization of $\mathbf{S}$ protein/vitronectin in human atherosclerotic versus arteriosclerotic arteries. Virchows Arch A Pathol Anat Histopathol 1989, 4I 4:309-3I 3.

26. Johnson LV, Leitner WP, Staples MK, Anderson DH: Complement activation and inflammatory processes in Drusen formation and age related macular degeneration. Exp Eye Res 200I, 73:887-896.

27. Mullins RF, Russell SR, Anderson DH, Hageman GS: Drusen associated with aging and age-related macular degeneration contain proteins common to extracellular deposits associated with atherosclerosis, elastosis, amyloidosis, and dense deposit disease. Faseb J 2000, 14:835-846.

28. Niculescu F, Rus HG, Porutiu D, Ghiurca V, Vlaicu R: Immunoelectron-microscopic localization of S-protein/vitronectin in human atherosclerotic wall. Atherosclerosis 1989, 78:197-203.

29. Ogawa T, Yorioka N, Yamakido M: Immunohistochemical studies of vitronectin, C5b-9, and vitronectin receptor in membranous nephropathy. Nephron 1994, 68:87-96.

30. Okada M, Yoshioka K, Takemura T, Akano N, Aya N, Murakami K, Maki S: Immunohistochemical localization of C3d fragment of complement and S-protein (vitronectin) in normal and diseased human kidneys: association with the C5b-9 complex and vitronectin receptor. Virchows Arch A Pathol Anat Histopathol 1993, 422:367-373.

31. Robert R, Jacobin-Valat MJ, Daret D, Miraux S, Nurden AT, Franconi $J M$, Clofent-Sanchez G: Identification of human scFVs targeting atherosclerotic lesions: Selection by single round in vivo phage-display. J Biol Chem 2006, 28 I (52):40 I35-40I 43.

32. van Aken BE, Seiffert D, Thinnes T, Loskutoff DJ: Localization of vitronectin in the normal and atherosclerotic human vessel wall. Histochem Cell Biol 1997, I 07:313-320.

33. Lommatzsch A, Hermans P, Muller KD, Bornfeld N, Bird AC, Pauleikhoff $D$ : Are low inflammatory reactions involved in exudative age-related macular degeneration?: Morphological and immunhistochemical analysis of AMD associated with basal deposits. Graefes Arch Clin Exp Ophthalmol 2008, 246:803-8I0.

34. Crabb JW, Miyagi M, Gu X, Shadrach K, West KA, Sakaguchi $H$, Kamei M, Hasan A, Yan L, Rayborn ME, et al:: Drusen proteome analysis: an approach to the etiology of age-related macular degeneration. Proc Natl Acad Sci USA 2002, 99: | 4682- | 4687.

35. Luibl V, Isas JM, Kayed R, Glabe CG, Langen R, Chen J: Drusen deposits associated with aging and age-related macular degeneration contain nonfibrillar amyloid oligomers. J Clin Invest 2006, I 1 6:378-385.

36. Mullins RF, Aptsiauri N, Hageman GS: Structure and composition of drusen associated with glomerulonephritis: implications for the role of complement activation in drusen biogenesis. Eye 200I, I 5:390-395.

37. Tomasini BR, Mosher DF: Conformational states of vitronectin: preferential expression of an antigenic epitope when vitronectin is covalently and noncovalently complexed with thrombin-antithrombin III or treated with urea. Blood 1988, 72:903-912.

38. Zhuang $\mathrm{P}$, Blackburn MN, Peterson $\mathrm{CB}$ : Characterization of the denaturation and renaturation of human plasma vitronectin. I. Biophysical characterization of protein unfolding and multimerization. J Biol Chem 1996, 27 I:|4323-|4332.

39. Zhuang P, Li H, Williams JG, Wagner NV, Seiffert D, Peterson CB: Characterization of the denaturation and renaturation of human plasma vitronectin. II. Investigation into the mechanism of formation of multimers. I Biol Chem 1996, 27 I:|4333-14343.

40. Anderson DH, Talaga KC, Rivest AJ, Barron E, Hageman GS, Johnson LV: Characterization of beta amyloid assemblies in drusen: the deposits associated with aging and age-related macular degeneration. Exp Eye Res 2004, 78:243-256.

4I. Rocken C, Tautenhahn J, Buhling F, Sachwitz D, Vockler S, Goette A, Burger T: Prevalence and pathology of amyloid in atherosclerotic arteries. Arterioscler Thromb Vasc Biol 2006, 26:676-677.

42. Vallet PG, Guntern R, Hof PR, Golaz J, Delacourte A, Robakis NK, Bouras C: A comparative study of histological and immunohistochemical methods for neurofibrillary tangles and senile plaques in Alzheimer's disease. Acta Neuropathol (Berl) 1992, 83: $170-178$

43. Barghorn S, Nimmrich V, Striebinger A, Krantz C, Keller P, Janson B, Bahr M, Schmidt M, Bitner RS, Harlan J, et al.: Globular amyloid beta-peptide oligomer - a homogenous and stable neuropathological protein in Alzheimer's disease. J Neurochem 2005, 95:834-847.

44. Cleary JP, Walsh DM, Hofmeister JJ, Shankar GM, Kuskowski MA, Selkoe DJ, Ashe KH: Natural oligomers of the amyloid-beta protein specifically disrupt cognitive function. Nat Neurosci 2005, 8:79-84.

45. Lue LF, Kuo YM, Roher AE, Brachova L, Shen Y, Sue L, Beach T, Kurth $J \mathrm{H}$, Rydel RE, Rogers J: Soluble amyloid beta peptide concentration as a predictor of synaptic change in Alzheimer's disease. Am J Pathol 1999, I 55:853-862.

46. McLean CA, Cherny RA, Fraser FW, Fuller SJ, Smith MJ, Beyreuther $\mathrm{K}$, Bush Al, Masters CL: Soluble pool of Abeta amyloid as a determinant of severity of neurodegeneration in Alzheimer's disease. Ann Neurol 1999, 46:860-866.

47. Walsh DM, Klyubin I, Fadeeva JV, Cullen WK, Anwyl R, Wolfe MS, Rowan MJ, Selkoe DJ: Naturally secreted oligomers of amyloid beta protein potently inhibit hippocampal long-term potentiation in vivo. Nature 2002, 4 I 6:535-539.

48. Kayed R, Head E, Thompson JL, Mclntire TM, Milton SC, Cotman CW, Glabe CG: Common structure of soluble amyloid oligomers implies common mechanism of pathogenesis. Science 2003, 300:486-489.

49. Sanbe A, Osinska H, Saffitz JE, Glabe CG, Kayed R, Maloyan A, Robbins J: Desmin-related cardiomyopathy in transgenic mice: a cardiac amyloidosis. Proc Natl Acad Sci USA 2004, 101:10132-10136.

50. Sanbe A, Osinska H, Villa C, Gulick J, Klevitsky R, Glabe CG, Kayed $R$, Robbins J: Reversal of amyloid-induced heart disease in desmin-related cardiomyopathy. Proc Natl Acad Sci USA 2005, I 02:13592-13597.

5I. Hageman GS, Luthert PJ, Victor Chong NH, Johnson LV, Anderson $\mathrm{DH}$, Mullins RF: An integrated hypothesis that considers drusen as biomarkers of immune-mediated processes at the RPE-Bruch's membrane interface in aging and age-related macular degeneration. Prog Retin Eye Res 200I, 20:705-732.

52. Kayed R, Sokolov Y, Edmonds B, Mclntire TM, Milton SC, Hall JE, Glabe CG: Permeabilization of lipid bilayers is a common conformation-dependent activity of soluble amyloid oligomers in protein misfolding diseases. J Biol Chem 2004, 279:46363-46366.

53. Stine WB Jr, Dahlgren KN, Krafft GA, LaDu MJ: In vitro characterization of conditions for amyloid-beta peptide oligomerization and fibrillogenesis. I Biol Chem 2003, 278: I I6II2-II622.

54. Bucciantini M, Giannoni E, Chiti F, Baroni F, Formigli L, Zurdo J, Taddei N, Ramponi G, Dobson CM, Stefani M: Inherent toxicity of aggregates implies a common mechanism for protein misfolding diseases. Nature 2002, 4 I 6:507-5 I I.

55. Chiti F, Dobson CM: Protein misfolding, functional amyloid, and human disease. Annu Rev Biochem 2006, 75:333-366.

56. Baskakov IV, Legname G, Baldwin MA, Prusiner SB, Cohen FE: Pathway complexity of prion protein assembly into amyloid. J Biol Chem 2002, 277:2 II 40-21।48.

57. Bucciantini M, Calloni G, Chiti F, Formigli L, Nosi D, Dobson CM, Stefani M: Prefibrillar amyloid protein aggregates share common features of cytotoxicity. J Biol Chem 2004, 279:3 I 374-3 I 382.

58. Chiti F, Bucciantini M, Capanni C, Taddei N, Dobson CM, Stefani M: Solution conditions can promote formation of either amyloid protofilaments or mature fibrils from the HypF N-terminal domain. Protein Sci 2001, 1 0:254 I-2547.

59. Chromy BA, Nowak RJ, Lambert MP, Viola KL, Chang L, Velasco PT, Jones BW, Fernandez SJ, Lacor PN, Horowitz P, et al.: Self-assembly of Abeta(I-42) into globular neurotoxins. Biochemistry 2003, 42: $12749-12760$ 
60. Hartley DM, Walsh DM, Ye CP, Diehl T, Vasquez S, Vassilev PM, Teplow DB, Selkoe DJ: Protofibrillar intermediates of amyloid beta-protein induce acute electrophysiological changes and progressive neurotoxicity in cortical neurons. J Neurosci 1999, 19:8876-8884

61. Hoshi M, Sato M, Matsumoto S, Noguchi A, Yasutake K, Yoshida N, Sato K: Spherical aggregates of beta-amyloid (amylospheroid) show high neurotoxicity and activate tau protein kinase I/glycogen synthase kinase-3beta. Proc Natl Acad Sci USA 2003, 100:6370-6375.

62. Janson J, Ashley RH, Harrison D, Mclntyre S, Butler PC: The mechanism of islet amyloid polypeptide toxicity is membrane disruption by intermediate-sized toxic amyloid particles. Diabetes 1999, 48:49|-498.

63. Zhu M, Han S, Zhou F, Carter SA, Fink AL: Annular oligomeric amyloid intermediates observed by in situ atomic force microscopy. J Biol Chem 2004, 279:24452-24459.

64. Demuro A, Mina E, Kayed R, Milton SC, Parker I, Glabe CG: Calcium dysregulation and membrane disruption as a ubiquitous neurotoxic mechanism of soluble amyloid oligomers. J Biol Chem 2005.

65. Quist A, Doudevski I, Lin H, Azimova R, Ng D, Frangione B, Kagan B, Ghiso J, Lal R: Amyloid ion channels: a common structural link for protein-misfolding disease. Proc Natl Acad Sci USA 2005, 102:10427-10432.

66. Jayasinghe SA, Langen R: Membrane interaction of islet amyloid polypeptide. Biochim Biophys Acta 2007.

67. Lashuel HA, Lansbury PT Jr: Are amyloid diseases caused by protein aggregates that mimic bacterial pore-forming toxins? $Q$ Rev Biophys 2006, 39:167-20I.

68. Fernandez-Escamilla AM, Rousseau F, Schymkowitz J, Serrano L: Prediction of sequence-dependent and mutational effects on the aggregation of peptides and proteins. Nat Biotechnol 2004, 22:1302-1306

69. Lynn GW, Heller WT, Mayasundari A, Minor KH, Peterson CB: A model for the three-dimensional structure of human plasma vitronectin from small-angle scattering measurements. Biochemistry 2005, 44:565-574.

70. Chiti F, Taddei N, Baroni F, Capanni C, Stefani M, Ramponi G, Dobson CM: Kinetic partitioning of protein folding and aggregation. Nat Struct Biol 2002, 9:137-143.

71. Otzen DE, Kristensen O, Oliveberg M: Designed protein tetramer zipped together with a hydrophobic Alzheimer homology: a structural clue to amyloid assembly. Proc Natl Acad Sci USA 2000, 97:9907-9912.

72. Pawar AP, Dubay KF, Zurdo J, Chiti F, Vendruscolo M, Dobson CM: Prediction of "aggregation-prone" and "aggregation-susceptible" regions in proteins associated with neurodegenerative diseases. J Mol Biol 2005, 350:379-392.

73. Izumi M, Yamada KM, Hayashi M: Vitronectin exists in two structurally and functionally distinct forms in human plasma. Biochim Biophys Acta 1989, 990:10I-108.

74. Preissner KT, Grulich-Henn J, Ehrlich HJ, Declerck P, Justus C, Collen $D$, Pannekoek H, Muller-Berghaus G: Structural requirements for the extracellular interaction of plasminogen activator inhibitor I with endothelial cell matrix-associated vitronectin. I Biol Chem 1990, 265: 18490-18498.

75. Hogasen K, Mollnes TE, Harboe M: Heparin-binding properties of vitronectin are linked to complex formation as illustrated by in vitro polymerization and binding to the terminal complement complex. J Biol Chem 1992, 267:23076-23082.

76. Kayed R, Head E, Sarsoza F, Saing T, Cotman CW, Necula M, Margol $\mathrm{L}$, Wu J, Breydo L, Thompson JL, et al:: Fibril specific, conformation dependent antibodies recognize a generic epitope common to amyloid fibrils and fibrillar oligomers that is absent in prefibrillar oligomers. Mol Neurodegener 2007, 2:18.

77. Wojciechowski K, Chang CH, Hocking DC: Expression, production, and characterization of full-length vitronectin in Escherichia coli. Protein Expr Purif 2004, 36:131-138.

78. Jin M, He S, Worpel V, Ryan SJ, Hinton DR: Promotion of adhesion and migration of RPE cells to provisional extracellular matrices by TNF-alpha. Invest Ophthalmol Vis Sci 2000, 41:4324-4332.
Publish with Bio Med Central and every scientist can read your work free of charge

"BioMed Central will be the most significant development for disseminating the results of biomedical research in our lifetime. "

Sir Paul Nurse, Cancer Research UK

Your research papers will be:

- available free of charge to the entire biomedical community

- peer reviewed and published immediately upon acceptance

- cited in PubMed and archived on PubMed Central

- yours - you keep the copyright

Submit your manuscript here:

http://www.biomedcentral.com/info/publishing_adv.asp
BioMedcentral 